\title{
PENGARUH MOTIVASI DAN GAYA KEPEMIMPINAN \\ TERHADAP KINERJA PEGAWAI \\ (STUDI PADA PEGAWAI DINAS PERINDUSTRIAN \\ PERDAGANGAN DAN KOPERASI KOTA PALEMBANG)
}

\author{
Yohanes Susanto \\ Dosen Program Pascasarjana UIGM Palembang \\ e-mail: yohanes@uigm.ac.id
}

\begin{abstract}
This study was purposed at examining the work motivation and leadership style on employee performance. The sample used in this study consisted of 15 respondents from 35 employees. The sampling method used is purposive sampling, the data analysis method used is multiple linear regression analysis. Based on the results of data analysis, the regression equation obtained was $Y=22.100+1.167 X 1+0.420 X 2+e$. The result of the research by using $t$-test that leadership style and work motivation have a significant positive influence on employee performance. The results simultaneously using F-test showed that all independent variables significantly affect employee performance coefficient determinant (R2) is 0,594 which means 59\% employee performance is explained by independent variables, where $41 \%$ is explained by other variables that are not followed.
\end{abstract}

Keywords: Work Motivation, Leadership Style, Employee Performance

\section{PENDAHULUAN}

Untuk menjalankan good governance yang baik, pemerintah daerah harus mempunyai kinerja yang baik, kinerja yang baik akan didapat dari pegawai yang bekerja dengan efisien dan efektif dan mempunyai etos kerja yang tinggi sehingga akan menghasilkan produktifitas tinggi. Sumber daya pemerintah tidak terlepas dengan masalah pemberdaya gunaan sumber daya aparatur, dengan demikian aspek kualitas akan terkait dengan pencapaian kinerja harus didukung dengan factor lain seperti motivasi dan gaya kepemimpinan.

Motivasi tidak hanya merupakan semangat untuk berperan serta secara aktif dalam proses organisasi, tetapi motivasi adalah menciptkan sikap dan perilaku seseorang agar melaksanakan tugas dengan semangat dan bertanggung jawab, dengan adanya motivasi kerja bagi pegawai, maka pegawai akan merasa dihargai, motvasi kerja adalah penting dalam rangka mencapai tujuan organisasi seperti pemenuhan kebuokoh sentral tuhan dan karir. Sedangkan pada organisasi motivasi kerja merupakan salah satu instrument dalam mencapai tujuan organisasi.

Di lain pihak peran kepemimpinan merupakan tokoh sentral dalam menjalankan suatu organisasi atau instansi, untuk itu seorang pemimpin harus mampu memberikan motivasi kepada stafnya agar dapat meningkatkan kinerja untuk kepentingan dinas yang lebih luas. Dari hasil survey penulis di 
lapangan ditemukan satu dinas yang mempunyai koordians yang cukup luas dan memerlukan seorang pemimpin yang cakap dan mampu membaca peluang serta juga harus di dukung oleh staf yang cerdas jujur dan loyalitas tinggi yaitu Dinas Perindustrian Perdagangan dan Koperasi Kota Palembang, dengan nomenklatur perangkat daerah mengkoordinir kepengurusan tiga instasi pusat dan daerah, yaitu bidang perindustrian, perdagangan dan koperasi.

Mengikuti uraian tersebut di atas,dapat disimpulkan bahwa ada pengaruh antara motivriasi dan gaya kepemimpinan dalam sebuah instansi pemerintah daerah terhadap pencapaian kinerja pegawai. Oleh karenanya penulis tertarik untuk melakukan penelitian yang dituangkan dengan judul Pengaruh Motivasi dan gaya Kepemimpinan terhadap kinerja Pegawai Dinas Perindustrian Perdagangan dan Koperasi Kota Palembang.

\section{TINJAUAN PUSTAKA}

\section{Kinerja}

Kinerja adalah apa yang dilakukan atau tidak dilakukan oleh karyawan (Robert L.Mathis 2006 :337) Mangkunegara (2005:67) kinerja adalah hasil kerja secara tertulis dan kualitas yang dicapai seseorang karyawan dalam melaksanakan tugasnya sesuai dengan tangung jawab yang diberikan kepadanya, sehingga kinerja adalah hasil dari suatu pekerjaan yang dapat diukur secara kuantitatif. Menurut L Mathis (2006) elemen-elemen kinerja yang di nilai adalah kuantitatif hasil kerja, kualitas hasil kerja, ketepatan waktu kerja, efisiensi kerja dan kerjasama.

Dari teori-teori di atas dapat disimpulkan bahwa yang dimaksud dengan kinerja adalah hasil kerja secara kualitas dan kuantitas yang dicapai seseorang karyawan dalam melaksanakan tugasnya sesuai dengan tanggung jawab yang diberikan kepadanya,sehingga kinerja adalah hasil dari suatu pekerjaan yang dapat diukur secara kuantitatif dengan menggunakan alat ukur tertentu, dan indikator penilaian kinerja penelitian ini meliputi ; (a)kemampuan pegawai membuat dan melaksanakan program kerja (b)mutu dan hasil kerja(c)prakarsa dan sikap(d)kemampuan bekerja dalam kelompok(e)kecermatan dalam bekerja.

\section{Motivasi}

Dalam kontek studi psikologi setiap, Abin syamsudin makmun (2003) mengemukakan bahwa untuk memahami motivasi individu dapat dilihat dari beberapa indikator, diantaranya : (1) durasi kegiatan, (2) frekuensi kegiatan, (3) persistensi kegiatan, (4) ketabahan, keuletan dan kemampuan dalam menghadapi rintangan dan kesulitan(5)devosi dan pengorbanan untuk mencapai tujuan, (6) tingkat aspirasi yang hendak dicapai dengan 
kegiatan yang dilakukan, (7) tingkat kualifikasi atau produk yang dicapai dari kegiatan yang dilakukan. Dalam kehidupan organisasi motivasi bagi setiap unsur pimpinan mempunyai arti sendiri. Motivasi menurut Dirahyusumidjo (1987: 173), (a) motivasi sebagai sesuatu yang penting (important subject) tiap pemimpin tidak boleh tidak harus bekerja bersama-sama dan melalui orang lain atau bawahan, untuk itu diperlukan kemampuan memberikan motivasi kepada bawahan, (b) motivasi sebagai sesuatu yang sulit (puzzling subject) motivasi tidak dapat diamati dan diukur secara pasti, untuk mengamati dan mengukur motivasi berarti harus mengkaji lebih jauh perilaku masingmasing bawahan.

Motivasi menurut jenisnya dibagi menjadi dua yaitu motivasi positif dan motivasi negative; motivasi positif adalah suatu dorongan yang mampu dan mengakibatkan timbulnya harapan yang dapat memuaskan dirinya baik secara material maupun psikologis, dengan adanya harapan ini seseorang akan bekerja sungguh-sungguh, ikhlas, penuh dedikasi dan loyalitas serta bertanggung jawab, motivasi dapat timbul dari sendiri seperti adanya kepuasan terhadap prestasi kerja, adanya rasa tanggung jawab yang besar, adanya keinginan untuk berkembang pada pekerjaan yang menyenangkan.
Motivasi positif dapat juga timbul dari luar diri sendiri seperti lingkungan kerja dapat menumbuhkan motivasi positif seperti kenaikan gaji berkala, kenaikan pangkat, promosi jabatan, pemberian fasilitas dan pemberian penghargaan dan lain sebagainya. Motivasi negative adalah suatu dorongan untuk bekerja yang didasarkan adanya rasa takut dan adanya tekanan dari luar sehingga motivasi negative tumbuh akibat ancaman dan paksaan dan motivasi ini tidak akan menjamin dapat meningkatkan prestasi kerja, justru akan melemahkan tanggung jawab, inisiatif dan kreativitas.

\section{Gaya Kepemimpinan}

Menurut Ralph Waite and Ronald Lippit yang dikutip Winardi (2007:79) Gaya kepemimpinan yaitu (a) Gaya otoriter adalah gaya kepemimpinan yang menggunakan pendekatan kekuasaan dalam mencapai keputusan dan pengembangan strukturnya, kekuasaan sangat dominan diterapkan, (b) Gaya Kepemimpinan Demokratis adalah gaya kepemimpinan yang ditandai suatu struktur yang pengembangannya menggunakan pendekatan cooperative, kepemimpinan Demokratif cenderung bermoral tinggi, dapat bekerjasama dan mengutamakan mutu kerja dan dapat dengan mudah menempatkan diri, (c) Gaya Kepemimpinan kendali bebas, adalah gaya kepemimpinan yang memberikan 
kekuasaan penuh kepada bawahannya, struktur organisasi ini bersifatlonggar dan pimpinan bersifat pasif.

Berdasarkan teori kepemimpinan yang dikemukakan di atas dapat disimpulkan bahwa yang dimaksud gaya kepemimpinan adalah strategi, sifat dan sikap seseorang untuk menggerakkan oranglain atau bawahan agar dapat melaksanakan tugas pekerjaan organisasi untuk mencapai tujuan yang telah ditetapkan

\section{Kerangka Berpikir}

Berdasarkan uraian sebelumnya, maka dapat dianalisis bahwa motivasi dan gaya kepemimpinan dapat mempengaruhi kinerja pegawai dan analisis ini dituangkan dalam model kerangka konseptual berikut ini:

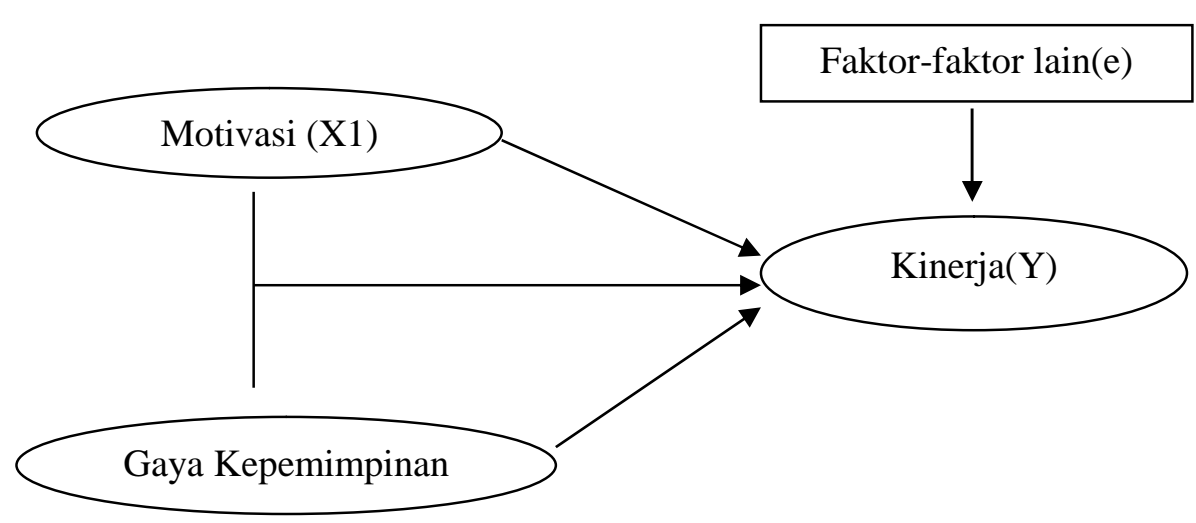

Kerangka Berpikir

Hipotesis Penelitian :

1. Terdapat pengaruh signifikan motivasi terhadap kinerja pegawai Dinas

Perindustrian Perdagangan dan Koperasi Kota Palembang

2. Terdapat pengaruh signifikan Gaya Kepemimpinan terhadap Kinerja pegawai Dinas Perindustrian Perdagangan dan Koperasi Kota Palembang

3. Terdapat pengaruh signifikan Motivasi dan Gaya Kepemimpinan secara bersama-sama terhadap Kinerja pegawai
Dinas Perindustrian Perdagangan dan

Koperasi Kota Palembang.

\section{METODE PENELITIAN}

\section{Populasi dan Sampel}

Populasi yang menjadi objek adalah seluruh pegawai di lingkungan Dinas Perindustrian Perdagangan dan Koperasi Kota Palembang, berjumlah 101 orang pegawai, dengan rincian jabatan Eselon III,IV dan Staf.

Teknik penetuan sampel menggunakan proporsional random sampling dengan rincian sebagai berikut : 


\begin{tabular}{llll}
\hline Nomor & Jabatan & Proporsi Uji Coba & Proporsi Sampel \\
\hline 1 & Eselon III & $6 / 101$ X $15=1$ & $6 / 101$ X $35=2$ \\
2 & Eselon IV & $18 / 101 \times 15=3$ & $18 / 101$ X $35=7$ \\
3 & Staf & $76 / 101 \times 15=11$ & $76 / 101$ X $35=26$ \\
& Jumlah & 15 & 35 \\
\hline
\end{tabular}

\section{Definisi Konseptual dan Operasional} Variabel.

a. Variabel Kinerja

Secara konseptual kinerja adalah prestasi atau kemampuan seseorang dalam melaksanakan tugas organisasi yang diberikan berdasarkan wewenang dan tanggung jawab yang dilimpahkan kepadanya.

Secara Operasional dimensi kinerja mencakup(1)kemampuan pegawai membuat dan melaksanakan program(2)mutu dan hasil kerja(3)prskarsa dan sikap(4)kemampuan kerja dalam kelompok(5)kecermatan dalam kerja.

b. Variable Motivasi

Secara konseptual variable motivasi adalah kekuatan dan daya dorong yang dimiliki seseorang dapat menmbulkan semangat dan antuisme dalam melaksanakan pekerjaab sehingga mencapai tujuan.

Secara operasional variable motivasi terdiri dari dimensi (1) semangat yang tinggi untuk berprestasi (2) ingin mendapatkan pengakuan (3) mendapatkan kompensasi (4) merasa puas dalam bekerja (5) lingkungan kerja yang nyaman.

c. Variabel Gaya Kepemimpinan

Secara konsetual gaya kepemimpinan adalah perilaku dan strategi, sebagai hasil kombinasi dari falsafah, ketrampilan, sifat, sikap yang sering diterapkan seseorang pemimpin ketika ia mencoba mempengaruhi kinerja bawahannya untuk melaksanakan tugas yang telah diterapkan dalam organisasi.

Secara operasional dimensi gaya kepemimpinan terdiri; (1) teknik hubungan antar manusia, (2) teknik menjadi teladan, dan (3) teknik persuasive dan pemberian perintah.

\section{Uji Instrumen}

a. Uji Validitas

Uji validitas dilakukan dengan membandingkan nilai $\mathrm{r}$ hitung (untuk setiap butir pertanyaan dapat dilihat pada kolom corrected item-),dengan $\mathrm{r}$ tabel dengan mencari degree of freedom $(\mathrm{df})=\mathrm{N}-\mathrm{kJ}$ Jikar hitung >r tabel, dan bernilai positif, maka pertanyaan (indikator) tersebut dikatakan valid (Ghozali, 2006).

b. Uji Reliabilitas Untuk mengukur reliabilitas dilakukan dengan uji statistic Cronbach $\operatorname{Alpha}(\alpha)$

Suatu variabel dikatakan reliabel jika memberikan nilai $\alpha>0,60$ (Nunnally dikutip oleh Ghozali, 2006). Analisis Regresi Linier Berganda Analisis regresi linier berganda yaitu 
analisi yang bertujuan untukmengetahui ada tidaknya hubungan ketergantungan, dan arah hubungan ketergantungan antara dua atau lebih variabel bebas dengan variabel terikatapakah positif atau negatif (Priyatno, 2008). Adapun persamaan regresi linier bergandanya adalah sebagai berikut :

$$
\mathrm{Y}=\mathrm{a}+\mathrm{b} 1 \mathrm{X} 1+\mathrm{b} 2 \mathrm{X} 2+\mathrm{b} 3 \mathrm{X} 3+\mathrm{e} .
$$

Di mana:

$\mathrm{Y}=$ Variabel dependen (kinerja pegawai)

$\mathrm{X} 1=$ Variabel independen (gaya

kepemimpinan)

$\mathrm{X} 2=$ Variabel independen(motivasi kerja)

$\mathrm{A}=$ Konstanta

b1,b2 = Koefisien regresi

$\mathrm{e}=$ Variabel lain yang tidak diteliti atau

dimasukkan dalam model

\section{Uji Hipotesis}

Pengujian hipotesis dilakukan untuk memperoleh kebenaran atas apayangtelah di hipotesiskan di bab tinjauan terdahulu

a. Uji Hipotesis Secara Simultan (Uji F)

Uji statistik $F$ pada dasarnya menunjukkan apakah semua variable dependen atau bebas yang dimasukkan berpengaruh secara bersama-sama terhadap variabel dependen atau terikat (Ghozali, 2006). Cara pengujiannya adalah berdasarkan probabilitas. Bila probabilitas lebih besar daripada 0,05 $(\alpha)$, maka variabel bebas secara serentak tidak berpengaruh variabel terikat. Sedangkan bila probabilitas lebih kecil daripada 0,05 $(\alpha)$, maka variabel bebas secara serentak berpengaruh terhadap variabel terikat. b. Uji Koefisien Determinasi (R2)

Koefisien determinasi (R2) dimaksudkan untuk mengukur kemampuan seberapa besar persentase variasi variabel bebas (independen) pada model regresi linear berganda dalam menjelaskan variasi variabel terikat (dependen) (Priyatno,2008). Dengan kata lain pengujian model menggunakan (R2), dapat menunjukkan bahwa variabel-variabel independen yang digunakan dalam model regresi linear berganda adalah variabelvariabel independen yang mampu mewakili keseluruhan dari variabel-variabel independen lainnya dalam mempengaruhi variable dependen, kemudian besarnya pengaruh ditunjukkan dalam bentuk persentase.

c. Uji t

Uji statistik $t$ pada dasarnya menunjukkan seberapa jauh pengaruh satu variabel penjelas/independen secara individual dalam menerangkan variasi variabel dependen Ghozali, 2006).

Cara melakukan uji $\mathrm{t}$ adalah sebagai berikut:

1. Membandingkan hasil besarnya peluang melakukan kesalahan (tingkatsignifikansi) yang muncul, dengan tingkat peluang munculnya kejadian (probabilitas) yang ditentukan sebesar 5\% atau 0,05 pada output: 
a. Apabila signifikansi $>0.05$ maka keputusannya adalah menerima Ho dan menolak Ha

b. Apabila signifikansi $<0.05$ maka keputusannya adalah menolak Ho dan menerima $\mathrm{Ha}$
2. Membandingkan nilai statistik $\mathrm{t}$ hitung dengan nilai statistik $\mathrm{t}$ tabel:

a. Apabila nilai statistik $t$ hitung $<$ nilai statistik tabel, maka Ho diterima

b. Apabila nilai statistik t hitung > nilai statistik tabel, maka Ho ditolak

\section{HASIL PENELITIAN DAN PEMBAHASAN}

Uji Validasi

\begin{tabular}{lcc}
\hline \multicolumn{1}{c}{ Indikator } & \multicolumn{1}{c}{ r.Hitung } & Keterangan \\
\hline Variabel Kinerja & & \\
Indikator 1 & 0,889 & Valid \\
Indikator 2 & 0,903 & Valid \\
Indikator 3 & 0,973 & Valid \\
Indikator 4 & 0,885 & Valid \\
Indikator 5 & 0,646 & Valid \\
Variabel Motivasi & & \\
Indikator 1 & 0,889 & Valid \\
Indikator 2 & 0,903 & Valid \\
Indikator 3 & 0,973 & Valid \\
Indikator 4 & 0,885 & Valid \\
Indikator 5 & 0,646 & Valid \\
Variabel Gaya Kepemimpinan & & \\
Indikator 1 & 0,973 & Valid \\
Indikator 2 & 0,661 & Valid \\
Indikator 3 & 0,582 & Valid \\
Indikator 4 & 0,889 & Valid \\
Indikator 5 & 0,973 & Valid \\
\hline
\end{tabular}

Uji Ralibilitas

\begin{tabular}{llll}
\hline Variabel & Crobach's Alpha & N of Items & Status \\
\hline Kinerja &, 766 & 15 & Reliabel \\
Motivasi &, 768 & 15 & Reliabel \\
Gaya Kepemimpinan &, 767 & 15 & Reliabel \\
\hline
\end{tabular}

Uji Persyaratan

a. Uji Normalitas

Uji Normalitas One-Sampel Kolmogoro-Sminov Test

\begin{tabular}{lrrr}
\hline N & Skor Kinerja(Y) & Skor Motivasi(X1) & Skor Gakep(X2) \\
\hline Normal Mean & 35 & 35 & 35 \\
Parameter a.b Std.Deviation & 86,66 & 84,97 & 84,80 \\
Most Extrem Absolute & 9,346 & 9,109 & 8,950 \\
Differences Positif & -185 & -169 & -161 \\
$\quad$ Negatif & -142 & -169 & -161 \\
Kolmogorov-Smirnov Z & -185 & -131 & -149 \\
& 1.097 & 1.002 & 952 \\
Asymp. Sig (2-tailed) & 180 & 268 & 325 \\
& & & \\
\hline
\end{tabular}


b. Uji Homogenitas

\begin{tabular}{lrlrr}
\hline & \multicolumn{1}{l}{ Skor } & Skor & \multicolumn{2}{l}{ Skor } \\
& \multicolumn{1}{c}{ Kinerja(Y) } & Motivasi(X1) & & Gakep(X2) \\
\hline Chi-Squre & $11.800 \mathrm{a}$ & $6.571 \mathrm{~b}$ & $15.143 \mathrm{~b}$ \\
Df & 13 & 14 & 14 \\
Asymp. Sig & .544 & .950 & .368 \\
\hline
\end{tabular}

Nilai ketiga variable lebeih besar $\alpha=0,05$ dapat disimpulkan bahwa data populasi memiliki varian homogen

c. Uji Lineritas

Kinerja * Motivasi ( Anova Table)

\begin{tabular}{lllll}
$\begin{array}{l}\text { Sum of } \\
\text { Squares }\end{array}$ & Df & $\begin{array}{l}\text { Mean } \\
\text { Squares }\end{array}$ & F & Sig \\
\hline 2224,352 & 14 & 158.882 & 4.262 & 002 \\
1726.120 & 1 & 1726.120 & 46.306 & 000 \\
498.232 & 13 & 38.326 & 1.028 & 464 \\
745.533 & 20 & 37.277 & & \\
2969.886 & 34 & & &
\end{tabular}

Kinerja * Motivasi (Anova Table)

\begin{tabular}{lllll}
$\begin{array}{l}\text { Sum of } \\
\text { Squares }\end{array}$ & df & $\begin{array}{l}\text { Mean } \\
\text { Squares }\end{array}$ & F & Sig \\
\hline
\end{tabular}

Skor Kinerja(Y) Between(Combined)

$\begin{array}{rrrrr}2288.336 & 14 & 163.453 & 4.796 & 001 \\ 1473.936 & 1 & 1473.936 & 43.252 & 000 \\ 814.399 & 13 & 62.646 & 1.838 & 107 \\ 681.533 & 20 & 34.078 & & \\ 2969.886 & & & & \end{array}$

Gakep (X2) Deviation from Linerity

Within Groups

Total 2969.886

Tabel Anova di atas kedua variable lebih besar dari $\alpha=5 \%$ artinya antara variable Y dan X1 dan Y dan X2 sama-sama mempunyai hubungan yang linier.

Analisis Regresi

a. Regresi Linier Sederhana Pengaruh Motivasi(X1) terhadap Kinerja Pegawai(Y)

\begin{tabular}{|c|c|c|c|c|c|}
\hline Model & $\begin{array}{l}\text { Unstandardized } \\
\text { Coefficients B }\end{array}$ & $\begin{array}{c}\text { Unstandardized } \\
\text { Coefficients Std } \\
\text { Error }\end{array}$ & $\begin{array}{c}\text { Standardized } \\
\text { Coefficients } \\
\text { Beta }\end{array}$ & $\mathrm{t}$ & Sig \\
\hline 1 (Constant) & 20.190 & 9.876 & & 2.044 & .049 \\
\hline Skor & .782 & .116 & .762 & 6.76 & .000 \\
\hline Motivasi(X1) & & & & & \\
\hline
\end{tabular}

Pengaruh Gaya Kepemimpinan(X2) terhadap Kinerja Pegawai(Y)

\begin{tabular}{lrrrrr}
\hline \multicolumn{1}{c}{ Model } & $\begin{array}{c}\text { Unstandardized } \\
\text { Coefficients B }\end{array}$ & $\begin{array}{c}\text { Unstandardized } \\
\text { Coefficients Std } \\
\text { Error }\end{array}$ & $\begin{array}{c}\text { Standardized } \\
\text { Coefficients } \\
\text { Beta }\end{array}$ & t & Sig \\
\hline 1 (Constant) & 24.275 & 10.999 & & 2.207 & .034 \\
Skor Gakep(X2) & .736 & .129 & .704 & 5.702 & 000
\end{tabular}


Dari hasil analisis pengaruh motivasi(X1) terhadap kinerja pegawai(Y) di dapat persamaan $\mathrm{Y}=\mathrm{a}+\beta 1 \mathrm{X} 1+\mathrm{e}$ adalah positif $\mathrm{Y}$ $=20.190+0.762 \mathrm{X} 1+\mathrm{e}$ ini berarti setiap penambahan per satu satuan skor variable motivasi akan meningkatkan variable kinerja sebesar 0.762 .

b. Regresi Linier Berganda
Dari hasil analisis pengaruh Gaya kepeimimpinan (X2)terhadap kinerja pegawai( $(\mathrm{Y})$ dengan persamaan $\mathrm{Y}=\mathrm{a}+\beta 2 \mathrm{X} 2$ $+\mathrm{e}$ adalah positif $\mathrm{Y}=24.275+0.704 \mathrm{X} 2+\mathrm{e}$ ini berarti setiap penambahan per satuan skor variable gaya kepemimpinan, maka akan meningkatkan variable kinerja sebesar 0.704

Coefficient

\begin{tabular}{cccccc}
\hline Model & $\begin{array}{c}\text { Unstandardized } \\
\text { Coefficients B }\end{array}$ & $\begin{array}{c}\text { Unstandardized } \\
\text { Coefficients Std } \\
\text { Error }\end{array}$ & $\begin{array}{c}\text { Standardized } \\
\text { Coefficients } \\
\text { Beta }\end{array}$ & T & Sig \\
\hline $\begin{array}{c}\text { Constant) } \\
\text { Skor }\end{array}$ & 22.100 & 10.060 & & 2.197 & .035 \\
Motivasi(X1) & 1.198 & .432 & .1 .167 & 2.773 & 009 \\
$\begin{array}{c}\text { Skor Gaya } \\
\text { Kepemimpinan }\end{array}$ & .439 & .440 & -420 & -998 & .326 \\
\hline
\end{tabular}

Hasil dari analisis menunjukan bahwa $+0,420 \times 2+$ e ini berarti setiap penambahan koefisien regresi variable Motivasi(X1) $=$ per satuan variable (X1) Motivasi, maka 1,167 Gaya Kepemimpinan(X2) $=-0,420$ dan variable Kinerja akan meningkat sebesar 1,167 menghasilkan nilai konstanta 22,100 sehingga persamaan regresi linier berganda $\mathrm{Y}=\mathrm{a}+$ $\beta 1 \mathrm{X} 1+\beta 2 \mathrm{X} 2+\mathrm{e}$ atau $\mathrm{Y}=22,100+1,167 \mathrm{X} 1$ dan setiap pengurangan per satuan variable (X2) Gaya Kepemimpinan, maka veriabel Kinerja akan berkurang sebesar 0,420

\section{Uji Simultan (F)}

ANOVAb

\begin{tabular}{cccccc}
\hline Model & Sum of Squeres & df & Mean Squres & F & Sig \\
\hline 1 Regression & 1763.690 & 2 & 881.845 & 2.197 & $.000 \mathrm{a}$ \\
Residual & 1206.195 & .32 & .37 .694 & & \\
Total & .2969 .886 & .34 & & & \\
& & & & & \\
\hline
\end{tabular}




\section{Pengujian Hipotesis}

1. Uji Parsial(t)

\section{Hipotesis Pertama}

Ho. $\beta 1=0$ Tidak terdapat pengaruh positif dan signifikan motivasi terhadap kinerja Ha. $\beta 1>0$ Terdapat pengaruh positif dan signifikan motivasi terhadap kinerja

Karena nilai Sig diperoleh sebesar 0,000 maka Ho ditolak

Kesimpulan : Terdapat pengaruh positif dan signifikan motivasi terhadap kinerja

\section{Hipotesis Kedua}

Ho. $\beta 2=0$ Tidak terdapat pengaruh positif dan signifikan Gaya Kepemimpinan terhadap kinerja

Ha. $\beta 2>0$ Terdapat pengaruh positif dan signifikan Gaya Kepemimpinan terhadap kinerja

Karena nilai Sig diperoleh sebesar 0,000 maka Ho ditolak

Kesimpulan :Terdapat pengaruh positif dan signifikan Gaya Kepemimpinan terhadap kinerja

\section{Hipotesis Ketiga}

Ho. $\beta 2=0$ Tidak terdapat pengaruh positif dan signifikan motivasi dan Gaya Kepemimpinan terhadap kinerja

Ha. $\beta 2>0$ Terdapat pengaruh positif dan signifikan motivasi dan Gaya Kepemimpinan terhadap kinerja

Karena nilai Sig diperoleh sebesar 0,000 maka Ho ditolak
Kesimpulan : Terdapat pengaruh positif dan signifikan motivasi dan Gaya Kepemimpinan terhadap kinerja

\section{KESIMPULAN DAN IMPLIKASI MANAJEMEN}

Keseluruhan hasil analisis data penelitian disimpulkan sebagai berikut :

1. Motivasi berpengaruh positif dan signifikan terhadap kinerja pegawai Dinas Perindustrian Perdagangan dan Kopersi Kota Palembang

2. Gaya Kepemimpinan berpengaruh positif dan signifikan terhadap kinerja pegawai Dinas Perindustrian Perdagangan dan Koperasi Kota Palembang

3. Motivasi dan Gaya Kepemimpinan secara bersama-sama berpengaruh positif dan signifikan terhadap kinerja pegawai Dinas Perindustrian Perdagangan dan Kopersi Kota Palembang.

Sedangkan implikasi manajemen menunjukan bahwa upaya peningkatan kinerja pegawai dapat dilakukan melalui peningkatan Motivasi dan Gaya Kepemimpinan secara bersama-sama dalam Uji F sebesar 23,395 > 0,000 dan $\mathrm{R} 2=77,10 \%$ dan tidak dapat dipisahkan, penelitian ini hendaknya dapat dijadikan sebagai bahan pertimbangan kebijakan dalam penataan dan pembinaan pegawai dengan menerapkan Gaya Kepemimpinan dan Motivasi yang tepat. 


\section{DAFTAR PUSTAKA}

Achmad, Ruky, 2004., Sistem Manajemen Kinerja, Panduan praktis untuk merancang dan Meraih Kinerja Prima, Catatan Ketiga, Jakarta: PT. Gramedia Pustaka Utama.

Arikunto, Suharsimi, 1996., Prosedur Penelitian Suatu Pendekatan Pratek, Edisi Ketiga, Jakarta: PT. Reneka Cipta.

Aroef, Mathias, 1995., "Motivasi dan Produktivitas, Suatu pembahasan dengan kasus dalam produktivitas dan Tenaga kerja Indonesia", Kumpulan Kertas Kerja, J Rafianto (ed) Lembaga sarana informasi usaha dan produktivitas Pascasarjana UGM, Yogyakarta.

Bernadin, H,Jhon and Russel, 1998., Human Resources-Frameworks For General Manager, New York: Jhon Willey \& Inc.

Davis, Keith, and Jhon W, Newstrom, 2002., Perilaku dalam Organisasi, Edisi Ketujuh Jakarta: PT. Erlangga.

Gibson,James L,Jhon, M Ivancevich, 1991., Organization Behavior, New Jersey: Prentice-Hall Inc, Englewood Cliffs.

Hasibuan, H Malayu SP, 2000., Manajemen Sumber Daya Manusia, Jakarta: PT. Bumi Aksara.
Hadari, Nawawi, 2000., Manajemen Sumber Daya Manusia Untuk Bisnis yang Kompetitif, Yogyakarta: Penerbit UGM.

Husein, Umar, 2004., Riset Sumber Daya Manusia dalam Organisasi, Edisi Revisi, Jakarta: PT. Gramedia Pustaka Utama.

Maslow, Abraham A, 1993., Motivasi dan Keperibadian, Teori Motivasi dengan Pendekatan Heirarkhi Kebutuhan Manusia, Bandung: PT. Remaja Rosdakarya.

Miltha, Thoha, 2004., Perilaku Organisasi, Konsep Dasar dan Aplikasinya, Jakarta: PT. Raja Grafindo Persada.

Robins, Stephen P, 2006., Perilaku Organisasi, Jakarta: Indek.

Soeleman, Sukmalana, 2007., Manajemen Kinerja, Edisi Kedua, Jakarta: PT Intermedia Personalia Utama.

Suprihanto, Jhon, 1996., Penilaian Kinerja dan Pengembangan Karyawan, Yogyakarta: Penerbit BPFE.

Wahjosumidjo, 2001., Kepemimpinan dan Motivasi, Jakarta: PT. Ghalia Indonesia 